\title{
Title: Development and psychometric testing of the Gerontologic Nursing Competence (GeroNursingCom) instrument
}

\author{
Short running title: Developing and testing instrument
}

Abstract

Aim. The aim of this study was to develop and psychometrically test an instrument GeroNursingCom - that measures gerontologic nursing competence of nursing students. The objective of the study is to clarify gerontologic competencies generated by nursing education to further develop nursing education.

Design. An instrument development, including four phases guided by COSMIN guidelines, was implemented into the study.

Method. The development and testing of the GeroNursingCom instrument proceeded according to four distinct phases: 1) establishing a theoretical background; 2) testing face and content validity; 3) examining structural validity; and 4) testing internal consistency. The items of instrument were based on a theoretical framework developed from a comprehensive literature review and focus group interviews with experts $(n=27)$. Content validity was assessed by nine experts in gerontological nursing, while face validity was tested in a pilot study including 36 nursing students. Structural validity was examined with exploratory factor analysis with 267 nursing students from nine Finnish universities of applied sciences. The internal consistency was established with Cronbach's alpha. Multivariate statistical methods were used to conduct data analysis.

Results. The GeroNursingCom development and testing process yielded an instrument that includes 53 items across 11 factors, more specifically: i) appreciative encounters and interactions with older people (7 items); ii) medication for older people (5 items); iii) nutrition for older people (6 items); iv) safe living environment for older people (5 items); v) supporting the functioning of older people (9 items); vi) end-of-life care (4 items); vii) developing one's competencies (4 items); viii) supporting an older person's mental well-being (4 items); ix) supporting an older person's sexuality (3 items); $x$ ) guiding self-care among older people ( 3 items); and xi) responding to challenging situations (3 items). The instrument was able to explain $66.15 \%$ of the total observed variance, while Cronbach's alpha values for individual items varied from 0.75 to 0.89 . 
Conclusion. The GeroNursingCom instrument can be used to measure gerontologic nursing competence among nursing students in order to improve gerontological nursing education and/or geriatric care.

Impact. Graduating nursing students must develop versatile competencies to face the multiple needs of older patients. Assessing competencies is a useful way to examine students' current competencies and determine which parts of the curriculum need to be further developed to ensure students are prepared for gerontologic nursing.

Keywords (max 10): aged, older people, gerontologic nursing, older people nursing, elderly nursing, nursing students, professional competence + nursing competence, research instrument, instrument construction, instrument development

\section{INTRODUCTION}

Nursing competence covers a diverse combination of professional knowledge, skills, values and attitudes, and can be complemented by various attributes such as technical and practical skills, interpersonal skills and the ability to deliver safe and evidence-based care (Nursing and Midwifery Board on Ireland, 2019). The American Nurses Association (ANA) has defined gerontological nursing as an evidence-based nursing specialty that focuses on the process of aging and the protection and promotion of health and functioning (Bickford, 2018) which requires competencies related to patientand family-centered care (Bahrami, et al., 2019). Upon the completion of their studies, graduated nurses often possess competencies related to professional requirements, patient safety, and quality nursing care (Fukada, 2018). Recent growth in the older population (WHO, 2018) and the fact that most nursing students do not want to work with older people (Descholdt et al., 2010; Koskinen, et al. 2012) will both shape how gerontologic nursing will develop in the coming years. One step could be clearly outlining which competencies are critical to geriatric care (Authors blinded) so that educational institutions can discover if the nursing studies offer correct competencies and design studies that will educate uniformly excellent professionals to older people nursing. We designed an instrument to measure overall competence in gerontologic nursing because - to the best of our knowledge - no tool that focuses on the competencies required in geriatric care currently exists. As diverse competencies are required across different areas of health care, the presented instrument could be used to assess whether each nursing student has developed the right competencies to provide high-quality geriatric care. These competence evaluations could also be used to develop education; for example, evidence 
from numerous evaluations may highlight that a nursing curriculum should focus on certain skills necessary in geriatric care (Ghaffari, et al. 2016; Hsieh \& Chen, 2018)

\section{BACKGROUND}

General nursing competencies fall under four broad categories: professional values; communication and interpersonal skills; nursing practice, decision-making and leadership; and management and teamwork abilities (NMC, 2010). Clearly defined nursing competencies are key to effective nursing education. However, it has been challenging to establish one global definition, as many nations have applied specific definitions of competence (Fukada, 2018). It is quite worrying that the latest European Gerontological curriculum is from the year 2003 (WHO, 2003) while the growing older population is forcing health care to become more inclusive of older patients (WHO, 2015), i.e., nurses are expected to improve - or at least maintain - the functioning and well-being of older patients. As many of the ailments troubling geriatric patients cannot be cured, nurses in this field should be competent at maximizing health outcomes, promoting mental health, and providing evidence-based dementia care, emotional support, as well as optimal pain management and palliative care (Britten, et al., 2018; Bahrami, et al., 2018). The caring encounter is a foundation for nurses' work; as such, nurses must be open, communicative, sensitive and empathetic when interacting with patients (Holopainen, et al., 2019). Holopainen et al. (2014) identified presence, recognition, mutuality and availability as essential factors of successful patient encounters, while Wadensen et al. (2009) reported that nursing staff feel that older patients appreciate equality, integrity and security in caring encounters. James, Pejner \& Kihlgren (2019) also identified security to be of paramount importance in home care. To shed light on successful interactions, Goffman (1961) introduced the concept of focused interaction, during which people pay attention to both cognitive and visual aspects, such as eye contact. For instance, when communicating with dementia patients, nurses should be aware of different techniques, e.g., reminiscing and talking about the patient's life history (de Vries, 2013).

According to ICF (The International Classification of Functioning, Disability and Health), functioning includes interactions between health conditions, environmental characteristics and personal factors (WHO 2001). Therefore, nurses must realize that aging brings about functional changes that can compromise an elderly person's ability to live independently (Szanton, et al., 2014). As such, nurses should be empathetic to the fact that older people face physical, social and psychological challenges when living with a chronic condition (Abdi, et al., 2019). Eloranta (2009) proposed that nurses should be provided with clear processes for how to respond to older patients' challenges, strengthen these 
patients' abilities to live independently, and promote their everyday functioning. This could include focusing on the patient's current life situation, treating patients in a highly dignified manner, and considering the patient's personal wishes for how they would like to spend their remaining time (Department of health, 2008). Gerontological nurses must also be highly competent in the medical care of older people (Karttunen, 2019), as a large proportion of people 65 years and older take at least one medication (Keine, et al., 2019). This demonstrates why gerontological nurses must possess good pharmacological competence, as well as understand and follow the guidelines for preparing and administering medications (Karttunen, et al. 2019). In addition to polypharmacy, nutritional vulnerability increases with age (Harbottle, 2019; WHO, 2020a). Nutrition does not only affect overall well-being, but can also contribute to the emergence and prevention of diseases. After all, many of the diseases that afflict older people are the result of malnutrition (WHO, 2020a). A patient's diet may impact their mood and well-being; as such, nurses should pay attention to patients who require help with unhealthy weight gain, adequate hydration and responsible alcohol consumption (Harbottle, 2019).

Several instruments have already been designed to build a comprehensive understanding of gerontological nursing, along with nurses' and nursing students' competencies. However, none of these instruments were designed to evaluate the broad range of competencies that are required in versatile care settings. For instance, two distinct instruments were developed with a focus on the homecare or assisted living setting. Bing-Jonsson et al. (2014) developed the Nursing Older People-Competence Evaluation Tool evaluation instrument to measure competencies which are essential to nurses working in elderly care homes or institution-based health care. The tool measures nurses' knowledge, skills and personal attributes. It includes various categories, but nevertheless lacks items related to guidance and self-care, the living environment, nutrition and an older person's sexuality, all of which were identified as essential areas of healthy and active aging by WHO (2015). Kiljunen's (2019) the Nurse Competence in Care Home Scale instrument measures nurse's competencies in the elderly care home setting. Hence, it adopts an institutional point of view and includes lots of items which consider the elderly person as a resident. Nursing students' attitudes towards gerontologic nursing have been studied using Kogan's KAOP-instrument (Kogan, 1961), which has been applied in several international studies (e.g. Bakan, et al. 2018; Salin et.al 2020; Söderhamn, et al, 2001). In a previous study we found gerontologic nursing to require a wide range of competencies, such as skills related to caring for, interacting with and promoting health and well-being among older people, along with clinical and ethical competence (Authors-blinded). For this reason, the development of a new 
instrument was seen as necessary for further studying and measuring gerontologic nursing competence among nurses working with older people across diverse professional settings.

\section{THE STUDY}

Aim

The study aimed to develop and psychometrically test an instrument - GeroNursingCom that measures gerontologic nursing competence of nursing students. The objective of the study is to clarify gerontologic nursing competencies generated by nursing education to further develop the nursing education.

\section{Methodology}

The instrument development process spanned four phases: 1) establishing a theoretical background from which items could be derived;2) testing face and content validity; 3) examining structural validity; and 4) testing internal consistency of the instrument (see Figure 1). The first phase of the instrument development process began with a thorough examination of the literature, during which concepts that would be included in the framework were defined. An analysis of the gerontologic nursing curriculum was also conducted to further refine the framework, and focus group interviews with 27 experts in gerontologic nursing formed the basis for content validity (DeVellis, 2012). The experts were invited by email and later interviewed by a researcher (author-blinded) in the interviewee's wished environment. The interviews were recorded, transcripted, and analyzed by one researcher (authors-blinded) and confirmed by three other researchers (authors-blinded). The inductive content analysis has been separately reported in the Authors-blinded publication.

During the second phase, face and content validities of the instrument were evaluated using a pilot test and two rounds of assessment by nine gerontological nursing experts, respectively. Content Validity Index measurements progressed in two steps as proposed by Lynn (1986). The cut-off for an acceptable CVI value was set at 0.90 according to previous empirical evidence (Polit et al., 2007). The pilot test was performed to assess the face validity of the instrument, data collection practicality and how well participants understood specific items (Munro, 2005).

The third phase of the study covered structural validity testing, with principal component analysis (PCA) applied first to ensure the items correlated and cross-loading were identified, which were later 
verified with explorative factor analysis (EFA). The performed EFA employed principal axis factoring and Promax rotation. The Kaiser-Meyer-Olkin test (KMO) and Bartlett's test of Sphericity were performed to examine sample adequacy; when the KMO-level > 0.60 indicates for good satisfactory and Bartlett's significance level as p-value 0.05 (Pett, et. al., 2003; Hair, et al., 2010). In order to determine the number of factors, the cut-off for item loading to a factor was set at 0.400 in order to improve accuracy (DeVellis, 2012) and Kaiser's (Kaiser, 1960) eigenvalue-rule of 1.0 to represent the amount of information captured by each factor (Munro, 2005; DeVellis, 2012).

In the fourth phase, the internal consistency was measured by calculating Cronbach's alpha. To be considered reliable, all of the items of a newly developed instrument should demonstrate Cronbach's alpha values $\geq 0.70$, with most researchers considering a threshold of Cronbach's alpha $\geq 0.80$ a better indicator of reliability (DeVon, et al., 2007). The structural validity was tested using IBM SPSS (V.25; IBM Corporation, Armonk, NY) software and the instrument's methodological quality evaluated by using the COSMIN checklist (Mokkink, et al., 2010).

<insert figure 1 about here>

\section{Participants}

Phase I

For establishing the theoretical framework of the study, 27 gerontologic nursing experts were invited via contact person to participate to five focus group interviews. The themes of the interviews have been compiled from four universities of applied sciences' curricula. The inclusion criteria of focus group interviewees were experts of gerontologic patient care, including nurses, geriatric physicians and nursing educators. The experts represented different fields of nursing, e.g. university hospitals, city hospitals, home care, and long-term care. The inclusion criteria were provided to contact person supporting participants recruiting for the study.

Phase II

The face and content validity of the instrument was conducted by nine nursing experts. The inclusion criteria were gerontologic patient care minimum of one year experience, including nurses, educators and students.

\section{Phases III \& IV}

The research data was collected from Finnish nursing students $(N=799 ; n=274)$ studying at nine universities of applied sciences participated in this study. Inclusion criteria for participation were being 
enrolled as a student in chosen university, having completed gerontologic nursing studies (or equivalent studies under a different name), and being in the final stages of studies. Students could not participate in the study if they had not completed any courses related to gerontological nursing.

An adequate sample size for the study was predetermined by counting at least five participants per item of the instrument, which is the minimum sample size for reliably assessing the structural validity of the instrument (DeVellis, 2012). The total response rate was 34\%. The data were examined for the presence and mechanism of missing values by using Missing at Random (MAR), Missing Completely At Random (MCAR) and Missing Not at Random (MNAR) commands, with no detection of missing values. Multivariate outliers $(n=7)$ were detected based on Mahalanobis distance and Mardia's kurtosis calculations, with the cut-off set as p-value < 0.001 . The final sample of 267 nursing students was used to validate the GeroNursingCom instrument.

\section{Data collection}

Data were collected electronically through Webropol software (V3.0; Webropol Oy, Helsinki, Finland), with students sent a link to participate between May and November 2019. A total of nine universities of applied sciences were randomly selected according to their geographical locations within Finland. The participants answered the questionnaire during a previously agreed lesson or received a link via email by the contact person at their organization. In the case of students contacted via email, a reminder email was sent after one week. The invitation to participate contained information about the study aim, methods of data collection, ethical conduct of research, and how the research could benefit nursing education, along with the researchers' contact details and a link to the questionnaire. The questionnaire included 12 background questions and 83 items of the GeroNursingCom instrument. Data were collected in Finnish and based on pre-testing, it has taken on average15-20 minutes to respond.

\section{Instrument}

The newly developed Gerontologic Nursing Competence (GeroNursingCom) instrument consists of background questions and 11 sub-dimensions with a total of 53 items: i) Appreciative encounters and interactions with older people (7 items); ii) Medication for older people (5 items); iii) Nutrition for older people (6 items); iv) Safe living environment for older people (5 items); v) Supporting the functioning of older people(9 items); vi) End-of-life care (4 items); vii) Developing 
one's competencies (4 items); viii) Supporting an older person's mental well-being (4 items); ix) Supporting an older person's sexuality (3 items); $x$ ) Guiding self-care among older people (3 items); and xi) Responding to challenging situations ( 3 items). The 12 background questions were used to collect information on respondents' year of birth, gender, previous education and work experience, study motivation, type of study and study success. Respondents score each item using a four-point continuous scoring Likert scale (1 - Completely disagree; 2 - Partially disagree; 3 - Partially agree; 4 - Completely agree) to get specific responses of their competence (Lozano, et al., 2008). The neutral option for scoring (e.g., neither disagree or neither agree) was not optional in competence measurement since a certain level of competence was expected from the students. The instrument was originally developed in the Finnish language, was forward-backward translated into English and then backward translated into Finnish, after which the instrument was evaluated by a panel of content experts according to established scientific practices for the translation of instruments (WHO, 2020b). English version of the instrument needs to be additionally validated in an international context study.

\section{Ethical considerations}

The instrument presented in this research was developed to build competence among gerontological nursing students as well as improve geriatric care curricula. As is commonplace in research containing external participants, ethical perspectives, along with the societal value of the proposed study, were considered prior to data collection and expert panels (Stang, 2015). A contact person provided participants information about the research, explained informed consent, and clarified their freedom of determination. Furthermore, the researchers never had access to the participants' email addresses or personal information to reduce bias (Polit \& Beck, 2012). Participants agreed to participate in the study and anonymously share the provided data with researchers at the start of the questionnaire. Students were not asked to provide reasons for their decision not to participate since the study included voluntary participation. Permission to conduct this study was obtained from nine Finnish universities of applied sciences (Personal Data Act 523/1999).

\section{RESULTS}

\section{Participants}

A majority (86\%) of the total 267 participants were female (see table 1). The participants were between 21 and 57 years old, with $43 \%$ in their fourth year of nursing studies. In terms of educational background, $32 \%$ of the participants were practical nurses, $44 \%$ were high school graduates, and $24 \%$ 
reported other professional backgrounds. Furthermore, a clear majority (65\%) of the students had previous experience of working in health care.

< insert new table 1 about here>

\section{GeroNursingCom development and testing process}

The results are presented according to the four phases of GeroNursingCom instrument development and psychometric testing, more specifically: 1) establishing a theoretical background; 2) testing face and content validity; 3) examining structural validity; and 4) testing internal consistency of the instrument

\section{Phase I - theoretical background establishment}

During the first step of GeroNursingCom instrument development - the creation of a theoretical framework - concepts that were related to geriatric care and which could be numerically measured were identified from previously published research. The theoretical background was formed from existing literature on gerontologic nursing competencies (Bickford, 2018; Dijkman, et al., 2016; Fukada, 2018; McConnell, 2009; WHO, 2003), ethics in nursing for older people (Suhonen, et al., 2010), how geriatric care is covered in nursing education (Edelstein, 2011; Koh, 2012), and Finnish national regulations of general nursing competencies (Eriksson, et al., 2015), along with an analysis of the current gerontologic nursing curricula at four Finnish universities of applied sciences. This analysis of four separate curricula was used to identify the themes for focus group interviews, which were pretested with four gerontologic nursing experts. The themes identified in the literature review were elderly health and functional ability, theoretical knowledge of gerontological/geriatric nursing, control of patient and relatives, multi-professional co-operation and implementation of nursing, and nursing values and ethical principles (Authors-blinded). The themes were used in focus group interviews, of which as a result of these interviews, 196 codes were identified. These codes were then further analysed and categorized by four of the researchers into 82 subcategories, 32 categories, and 16 main themes. The main themes were later grouped into five thematic areas that described the main competencies required for successful geriatric care, namely, caring for older people, interacting with older people, promoting health and well-being, clinical competence, and ethical competence (Authorsblinded). The codes were operationalized into 85 items in collaboration with the research team.

Phase II - face and content validity testing 
The face and content validity of GeroNursingCom was tested over two rounds of expert evaluation. During the first round of evaluation, nine experts were asked to evaluate the relevancy and clarity of the 85 items using a four-point Likert scale (from not relevant to highly relevant) (Polit et al. 2007). Experts were encouraged to add additional comments and new suggestions if they felt that certain relevant items were missing. The experts included geriatric care nurses, leaders, educators and students. After all of the experts had evaluated the items, the Content Validity Index (CVI) was computed for each item (I-CVI), and the CVI average (S-CVI/Ave) for the instrument was calculated by dividing the number of experts that had given higher scores (scores of either 3 or 4 ) by the total number of experts. After the first round of evaluation, the calculated S-CVI/Ave demonstrated acceptable relevance (0.86) and clarity (0.90). In order to improve the instrument, items which had received lower scores, i.e., I-CVI 0.63-0.78, were either modified ( 8 items) or deleted ( 2 items). The second round of evaluation resulted in S-CVI/Ave values of 0.99 and 0.98 for relevance and clarity, respectively. After the second round of evaluation, the instrument included 83 items, as no items had been deleted since the first round of evaluation, but three items had been modified. After the content validity testing, the 83-item instrument's comprehensibility was pilot tested on 36 nursing students using an online survey in the Webropol software (V3.0).

The pilot data were not included in this study. The students were asked to assess the comprehensibility and clarity of the instrument, as well as the clarity and length of the survey. Students were asked to respond to each item, and were given the possibility to comment on each item in the open question field. The pilot study results demonstrated that the questionnaire had adequate structure and an acceptable number of items. None of the items needed to be modified based on the students' evaluations.

\section{Phase III - structural validity testing}

Structural validity was tested using data from a large sample of nursing students $(n=267)$. The preliminary analysis applied principal component analysis (PCA) to identify inter-correlations between items. The PCA cut-off for items' loading to factors was set at $<0.400$. Based on the conducted PCA, a total of seven cross-loading items were removed; as a result, the revised instrument included a total of 76 items over 12 components. Next, exploratory factor analysis (EFA) with principal axis factoring and Promax rotation. The EFA results led to the additional removal of 23 cross-loading and low-loading $(<0.400)$ items. The Kaiser-Meyer-Olkin test (KMO) (0.929) and Bartlett's test of Sphericity $(8545.475 ; \mathrm{df}=1378 ; \mathrm{p}<0.001)$ demonstrated acceptable sample size. The final model 
demonstrated an eleven-factor structure and included a total of 53 items. The cumulative percentage of variance explained by the eleven factors was $66.15 \%$ (see Table 2, Supplementary file 1). The first factor (Appreciative encounters and interactions with older people; 7 items) explained $35.0 \%$ of the total variance, the second factor (Medication for older people; 5 items) explained $5.6 \%$ of the total variance, the third factor (Nutrition for older people; 6 items) explained $4.2 \%$ of the total variance, the fourth factor (Safe living environment for older people; 5 items) explained $3.7 \%$ of the total variance, the fifth factor (Supporting the functioning of older people; 9 items) explained $3.4 \%$ of the total variance, the sixth factor (End-of-life care; 4 items) explained 3.0\% of the total variance, the seventh factor (Developing one's competencies; 4 items) explained $2.5 \%$ of the total variance, the eighth factor (Supporting an older person's mental well-being; 4 items) explained $2.4 \%$ of the total variance, the ninth factor (Supporting an older person's sexuality; 3 items) explained $2.3 \%$ of the total variance, the tenth factor (Guiding self-care among older people; 3 items) explained $2.1 \%$ of the total variance, and the eleventh factor (Responding to challenging situations; 3 items) explained 1.9\% of the total variance.

Phase IV - internal consistency testing

The reliability of the 53 items was assessed using Cronbach's alpha, with internal consistency ranging from 0.75 to 0.89 . The first factor (Appreciative encounters and interactions with older people; 7 items) explained 0.83; the second factor (Medication for older people; 5 items) explained 0.89; the third factor (Nutrition for older people; 6 items) explained 0.89; the fourth factor (Safe living environment for older people; 5 items) explained 0.84; the fifth factor (Supporting the functioning of older people; 9 items) explained 0.86; the sixth factor (End-of-life care; 4 items) explained 0.83; the seventh factor (Developing one's competencies; 4 items) explained 0.79; the eighth factor (Supporting an older person's mental well-being; 4 items) explained 0.88; the ninth factor (Supporting an older person's sexuality; 3 items) explained 0.81 ; the tenth factor (Guiding self-care among older people; 3 items) explained 0.75; and the eleventh factor (Responding to challenging situations; 3 items) explained 0.83. The Cronbach's alpha for the entire instrument was 0.96 .

< insert Table 2 about here>

\section{DISCUSSION}

The purpose of this study was to develop and psychometrically test an instrument (GeroNursingCom) that measures gerontological nursing competence among nursing students. The instrument is intended 
to measure a student's overall gerontological competence based on eleven distinct sub-dimensions of geriatric care. Further testing with a larger group of participants, most preferably international participants, would be necessary to determine its structural and cultural validation and whether the instrument is applicable to registered nurses for developing continuous education. Furthermore, the presented instrument can be used to develop nursing education. Previous instruments have been designed to investigate nurses' competencies in institutional health care (Bing-Jonsson, et al., 2014), care home (Kiljunen, et al., 2019), and various hospital environments (Meretoja, et al., 2004). Furthermore, an earlier instrument was developed to gauge nurses' or nursing students' attitudes towards older people (Kogan, 1961). We designed GeroNursingCom to cover a broader range of competencies than earlier instruments so that our instrument would be applicable to a wide range of nursing settings.

Upon graduation, a nurse may work anywhere in the field of nursing, which means that they should have at least some gerontological nursing competence. For future nurses to genuinely want to work with older people, it is essential that they understand - and are able to provide - holistic care. The holistic nursing approach and person-centered care are essential themes in gerontological nursing, especially in nursing homes (McCormack, 2004; McGilton, et al, 2012), and several countries have developed models for how to bring the best evidence-based, person-centered care into practice (Corazzini, et al, 2016). In person-centered care, nurses focus on treating older people as individuals who have their own habits and environmental needs (Koren, 2010). Furthermore, a crucial part of the nurse-patient partnership is maintaining older patients' capacities and abilities (Mitchell \& McCance, 2012). Hence, an appreciative interaction is based on person-centered thinking, i.e., a nurse takes various perspectives (the organization's as well as the patient's and their family's) into account when interacting with older people (Holroyd-Leduc, et al., 2016). The factors of the developed GeroNursingCom instrument represent several aspects of the multidimensional concept of holistic care and are based on theoretical framework (Authors blinded), which was expanded with validation reported in this study.

The whole comprises the individual, environmental, and system levels (Savage, 2019). When the individual perspective is considered, nurses either work alone, which requires self-management, or in a team (Fukada, 2018), and interact with health care stakeholders in multiple ways, verbally, in writing and/or through assistive devices (Kourkouta \& Papathanasiou, 2014), which requires ample culturally competence (Blanchet, et al, 2017). As computer skills are now considered part of life-long learning and high quality of life (González, et al, 2015), nurses are responsible for helping older people 
- who are becoming increasingly interested about learning new skills - adapt to new technologies (Vaportzis, et al., 2017). Future generations of older people will use computers without problems (Wandke, et al.2012), meaning that technology will become a common tool in the nurse-patient relationship in the near future. Nurses, as individual carers, have their own specific competencies in clinical nursing, caring for older people, ethical issues, and health promotion (Authors-blinded). Part of a nurse's job is being aware of their own competencies and realizing when they need to develop skills to provide high-quality care to their patients. For example, nurses should be understanding the diseases of older patients, i.e., which changes are a part of normal aging (Barrett \& Gumber, 2018; Hahr, 2019) and which changes, e.g., memory disorders, are the result of a disease. Furthermore, the various spheres of the whole often interact; notably, nurses should be competent at preparing and administering the right medications to older people, yet the system should also provide clear procedures to avoid medication errors (Brady, et al, 2009).

Regarding the environmental and system level, it is important that health care systems are efficient and that nurses understand the diverse ways in which the organization they are a part of can support them in their work. The system must also employ the correct technological solutions (Haufe, et al., 2019), i.e., provision of guidance and documentation (Selvi, 2017), to provide high-quality care. Robust health care systems include large multi-professional team that can effectively care for older people; the nurses - on an individual level - should know how to cooperate with their team members in different situations, e.g., how terminal care patients are cared for during every hour of the day.

The presented instrument measures a nurse's competence in applying holistic and person-centered nursing to older people, and considers individual, environmental and system levels. It is important to note that the internal consistency and validity of the instrument should be verified by collecting data from experienced nurses in both Finland and abroad. The instrument's reliability, as well as the clarity and relevance of individual items, was assessed by panel of nine experts, which exceeds the recommended expert panel size of seven (DeVon, et al., 2007). The face validity, which describes suitability and comprehensibility, was tested in a pilot study that included nursing students who are familiar with the vocabulary. This was important to confirming that the instrument measures what it was designed to measure (DeVellis, 2012). Following PCA and EFA, the validated instrument included a total of 53 items over eleven significant subscales: appreciative encounters and interactions with older people; medication for older people; nutrition for older people; safe living environment for older people; supporting the functioning of older people; end-of-life care; developing one's competencies; supporting an older person's mental well-being; supporting an older person's sexuality; 
guiding self-care among older people; and responding to challenging situations. A new instrument that includes many items may be found to explain a lower than desired percentage of total variance; therefore, it was essential to revisit and modify the items while considering the theoretical approach to instrument development. Individual items showed reliabilities ranging from $0.75-0.86$ according to Cronbach's alpha. The Cronbach's alpha value for the instrument was 0.96, which easily surpasses the common internal consistency minimum threshold of 0.70 (DeVon, et al., 2007). It should be noted that the researchers were in contact with the various organization contact persons several times to ensure successful data collection. Since the researchers could not contact students personally, the invitations and information delivery depended on the contact person in each organization. It should be stated that a larger sample could have improved the generalizability of the conclusions (DeVellis, 2012).

\section{Limitations}

The presented research included several limitations. The material was collected only from nursing students. In this way, the analyzed responses may have differed if registered nurses with substantial work experience had answered the questionnaire. The response rate could have been improved by involving more universities of applied sciences. However, the sample of nursing students was sufficiently large enough to statistically test the structural validity of the instrument. We further recommend validating the instrument with a larger sample, possibly including an international perspective to the study. The new structural validity can be enhanced with confirmatory factor analysis in order to confirm and further establish a theoretical framework of the studied phenomenon. The results can be generalized quite well to the graduating nursing students' population, but the presented results cannot be generalized to registered gerontological nurses without additional data collection. To strengthen the validity of the research, various study phases - i.e., planning, conducting and reporting - followed the COSMIN initiative guidelines of instrument development (Mokkink et al, 2010).

\section{CONCLUSION}

The newly developed GeroNursingCom instrument proved to be valid and reliable for measuring gerontologic nursing competencies among nursing students, but will require complementary studies to further strengthen the validity and applicability for more diverse target group. As such, there is now an instrument available for evaluating nursing student competencies in geriatric care that takes into account holistic and patient-centered care. However, it is important to state that this instrument has 
only been validated in the Finnish context. The provided assessments of nursing students' competence can be leveraged to identify which parts of nursing education need to be improved to ensure that graduated students are prepared to provide older patients with high-quality care. We feel that the presented instrument may enable nurses to self-evaluate the specific competencies necessary for participating in various types of gerontologic nursing. Furthermore, the insight provided by the instrument can be used to develop nursing curricula and design continuous education programs for registered nurses.

\section{ANONYMISED CONFLICT OF INTEREST STATEMENT}

The authors do not declare any conflict of interest.

\section{REFERENCES}

Abdi, S., Spann, A., Borilovic, J., de Witte, L. \& Hawley, M. (2019). Understanding the care and support needs of older people: A scoping review and categorisation using the WHO international classification of functioning, disability and health framework (ICF). BMC Geriatrics, 19.

Bahrami, M., Purfarzad, Z., Keshvari, M., Rafiei, M. \& Sivertsen, N. (2018). Emotional competence: A core competence in gerontological nursing in Iran. International Journal of Older People Nursing, 13(4), e12210.

Bahrami, M., Purfarzad, Z., Keshvari, M. \& Rafiei, M. (2019). The components of nursing competence in caring for older people in Iranian hospitals: A qualitative study. Iranian Journal of Nursing and Midwifery Research, 24(2), 124-130.

Bakan, A.B., Senay, K.A. \& Ela, V. (2018). Identification of nursing students' attitudes toward older people. Journal of Continuing Education in Nursing, 54(3), 284-292. DOI: https://doiorg.pc124152.oulu.fi:9443/10.1080/10376178.2018.1501276

Barrett, A \& Gumber, C. (2018). Feeling old, body and soul: The effect of aging body reminders on age identity. Journal of Gerontology Series B, 75(3), 625-629. DOI: doi.org/10.1093/geronb/gby085.

Bickford, C.J. (2018). A contemporary look at Gerontological Nursing. American Nurse Today, 13(6), 48.

Bing-Jonsson, P.C., Bjork, I.T., Hofoss, D., Kirkevold, M., \& Foss, C. (2014). Competence in advanced older people nursing: Development of 'Nursing older people - Competence evaluation tool'. International Journal of Older People Nursing, 10, 59-72. DOI: 10.1111/opn.12057.

Blanchet, G.A., Pepin, J. \& Gendron, S. (2017). Nurse-environment interactions in the development of cultural competence. International Journal of Nursing Education Scholarship, 14(1).

DOI: 10.1515/ijnes-2016-0028 
Brady, A-M., Malone, A-M. \& Fleming, S. (2009). A literature review of the individual and system factors that contribute to medication errors in nursing practice. Journal of Nursing Management, 17, 679-697.

Britten, N., Traynor, V., Osmond, T. \& Cheneoweth, L. (2018). Developing gerontological nursing competencies: An E-Delphi study. Australian Nursing \& Midwifery Journal, 25(7), 42.

Brown, J., Nolan, M. \& Davies, S. (2008). Bringing caring and competence into focus in gerontological nursing: A longitudinal, multi-method study. International Journal of Nursing Studies, 45(5), 654-667.

Corazzini, K. N., Meyer, J., McGilton, K. S., Scales, K., McConnell, E. S., Anderson, R. A., ... Ekman, I. (2016). Person-centered nursing home care in the United States, United Kingdom, and Sweden: Why building cross-comparative capacity may help us radically rethink nursing home care and the role of the RN. Nordic Journal of Nursing Research, 36, 59-61.

De Vries, K. (2013). Communicating with older people with dementia.

Nursing Older People, 25, 30-37. DOI: 10.7748/nop2013.05.25.4.30.e429.

Department of Health (2008). End of life care strategy - Promoting high quality care for all adults at the end of life. Retrieved

from: https://www.eapcnet.eu/Portals/0/adam/Content/LqML6Wj3xkKPO5rQoiex1A/Text/End\%20o f\%20Life $\% 20$ Care $\% 20$ Strategy\%20-

$\% 20$ Promoting $\% 20$ high $\% 20$ quality $\% 20$ care $\% 20$ for $\% 20$ all $\% 20$ adults $\% 20$ at $\% 20$ the $\% 20$ end $\% 20$ of $\%$ 20life $\% 20 . p d f$

Descholdt, M., de Casterle, B., \& Milisen, K. (2010). Gerontological care in nursing education programs. Journal of Advanced Nursing, 66, 139-48. DOI: 10.1111/j.1365-2648.2009. 05160.x

DeVellis, R.F. (2012). Scale development. Theory and applications (4th ed). Los Angeles, CA: SAGE Publications.

DeVon, H.A., Block, M.E., Moyle-Wright, P., Ernst, D.M., Hayden, S.J., Lazzara, D.J., ... Kostas-Polston, E., (2007). A psychometric toolbox for testing validity and reliability. Journal of Nursing Scholarship, 39, 155-164.

Dijkman, B., Roodbol, P., Achtschin-Stieger, S., Aho, J., Andruszkiewicz, A, Coffey, A., ... Sourtzi, P. (2016). European Core Competences Framework for Health and Social Care Professionals Working with Older People. Retrieved from: http://ellan.savonia.fi/index.php/results/eccfin- different-languages

Edelstein, J.A., Cheung, C.K., Voss, J.A. \& Kaas, M.J. (2011). The Faculty Learning About Geriatrics (FLAG) Program: Bringing together experts in geriatric nursing education. The Journal of Continuing Education in Nursing, 42(8), 378-384.

Eloranta, S. (2009). Supporting older people's independent living at home through social and health care collaboration (Doctoral dissertation). Department of Nursing Science, Faculty of Medicine, University of Turku, Finland. Annales Universitatis Turkuensis, Series D, Medica-Odontologica, 869. 
Eriksson, E., Korhonen, T., Merasto, M. \& Moisio, E-L. (2015). Sairaanhoitajan ammatillinen osaaminen - sairaanhoitajakoulutuksen tulevaisuus -hanke. Ammattikorkeakoulujen terveysalan verkosto ja Suomen sairaanhoitajaliitto ry. Porvoo, Finland: Bookwell Oy. (in Finnish).

Fukada, M. (2018). Nursing competency: Definition, structure and development. Yonago Acta Medica, 61(1), 1-7. DOI: 10.33160/yam.2018.03.001.

Ghaffari, F., Dehghan-Nayeri, N., Navabi, N. \& Seylani, K. (2016) Evaluation of the Master's curriculum for elderly nursing: a qualitative study. Clinical Interventions in Aging. 2016; 11: 13331342. DOI: $10.2147 / C I A . S 109004$

Goffman, E. (1961). Encounters: Two studies in the sociology of interaction. Cambridge, England: Ravenio Books.

González, A., Ramirez, M.P. \& Viadel, V. (2015). ICT Learning by older adults and their attitudes toward computer use. Current Gerontology and Geriatrics Research, 2015.

DOI: https://doi.org/10.1155/2015/849308.

Hahr, J.Y. (2019). Physiology of aging. Medical Hypotheses, 123, 83-85.

DOI: https://doi.org/10.1016/j.mehy.2018.12.016

Hair, J.F., Black, W.C., \& Babin, B.J. (2010). RE Anderson Multivariate data analysis: A global perspective. New Jersey, Pearson Prentice Hall.

Harbottle, L. (2019). The effect on nutrition on older people's mental health. British Journal of Community Nursing, 24(7), S12-S16.

DOI: org.pc124152.oulu.fi:8080/10.12968/bjen.2019.24.Sup7.S12

Haufe, M., Peek, S.T.M. \& Luijkc, K.G. (2019). Matching gerontechnologies to independent-living seniors' individual needs: Development of the GTM tool. Health Services Research, 19, 26. DOI: doi.org/10.1186/s12913-018-3848-5

Holopainen, G., Kasén, A. \& Nyström, L. (2014). The space of togetherness - a caring encounter. Scandinavian Journal of Caring Science, 28, 185-192. DOI: 10.1111/j.1471-6712.2012.01090. x.

Holopainen, G., Nyström, L. \& Kasén, A. (2019). The caring encounter in nursing. Nursing Ethics, 26(1), 7-16. DOI: 10.1177/0969733016687161.

Holroyd-Leduc, J., Resin, J., Ashley, L., Barwich, D., Elliott, J., Huras, P., .. Muscedere, J. (2016). Giving voice to older adults living with frailty and their family caregivers: Engagement of older adults living with frailty in research, health care decision making, and in health policy. Research Involvement and Engagement, 2, 23. DOI: 10.1186/s40900-016-0038-7

Hsieh, P-L. \& Chen, C-M. (2018). Nursing Competence in geriatric/Long term care curriculum Development for baccalaureate nursing programs: A systematic review. Journal of professional nursing. Sep-Oct 2018; 34 (5): 400-411. DOI: 10.1016/j.profnurs.2018.05.006 
James, I., Pejner, M.N. \& Kihlgren, A. (2019). Creating conditions for a sense of security during the evenings and nights among older persons receiving home health care in ordinary housing: A participatory appreciative action and reflection study. BMC Geriatrics, 19, 351.

Kaiser , H. F. (1960). The application of electronic computers to factor analysis . Educational and Psychological Measurement, 20, 141 - 151 .

Karttunen, M. (2019). Safe medication administration in long-term elderly care assessed by nursing staff (Doctoral dissertation). Faculty of Medicine, University of Oulu Graduate School, University of Oulu, Oulu, Finland. Acta Univ. Oul. D 1527, 2019.

Karttunen, M., Jokelainen, J., Sneck, S. \& Elo, S. (2019). Nurses' selfassessments of adherence to guidelines on safe medication preparation and administration in longterm elderly care. Scandinavian Journal of Caring Science, 34(1). DOI: 10.1111/scs.12712.

Keine, D., Zelek, M., Walker, J.Q. \& Sabbagh, M.N. (2019). Polypharmacy in an elderly population: Enhancing medication management through the use of clinical decision support software platforms. Neurology and Therapy, 8, 79-94. DOI: 10.1007/s40120-019-0131-6.

Kiljunen, O. (2019). Care home nursing professionals' competence in older people nursing (Doctoral dissertation). University of Eastern Finland, Kuopio, Finland. Dissertations in Health Sciences, 492.

Kogan, N. (1961). Attitudes toward older people: The development of a scale and an examination of correlates. The Journal of Abnormal and Social Psychology, 62(1), 4454. https://doi.org/10.1037/h0048053

Koh, L.C. (2012). Student attitudes and educational support in caring for older people - A review of literature. Nurse Education in Practice, 12, 16-20.

Koren, M. J. (2010). Person-centered care for nursing home residents: The culture-change movement. Health Affairs, 29, 312-317.

Kourkouta, L. \& Papathanasiou, I.V. (2014). Communication in nursing practice. Materia Sociomedica, 26(1), 65-67. DOI: 10.5455/msm.2014.26.65-67

Koskinen, S., Hupli, M., Katajisto, J. \& Salminen, L. (2012). Graduating Finnish nurse students' interest in gerontological nursing - A survey study. Nursing Education Today, 32(4), 356360. DOI: https://doi.org/10.1016/j.nedt.2011.05.015.

Lozano, L.M., García-Cueto, E., \&Muñiz, J. (2008). Effect of the number of response categories on the reliability and validity of rating scales. Methodology. Vol 4(2), 73-79

Lynn, M.R. (1986). Determination and quantification of content validity. Nursing Research, 35, 382385.

McConnel, E.S., Lekan, D., Bunn, M., Egerton, E., Corazzini, K.N., Hendrix, C.D. \& Bailey, D.E. (2009). Teaching evidence-based nursing practice in geriatric care settings. Journal of Gerontological Nursing, 35(4), 26-33. 
McCormack, B. (2004). Person-centredness in gerontological nursing: An overview of the literature. Journal of Clinical Nursing, 13(3), 31-38.

McGilton, K. S., Heath, H., Chu, C. H., Boström, A.-M., Mueller, C., Boscart, V. M., ... Bowers, B. (2012). Moving the agenda forward: A person-Centred framework in long-term care. International Journal of Older People Nursing, 7, 303-309.

Meretoja, R., Isoaho, H. \& Leino-Kilpi, H. (2004). Nurse Competence Scale: Development and psychometric testing. Journal of Advanced Nursing, 47(2), 124-

133. DOI: https://doi.org/10.1111/j.1365-2648.2004.03071.x

Mitchell, E.A. \& McCance, T. (2012). Nurse-patient encounters in the hospital ward, from the perspectives of older persons: An analysis using the Authentic Consciousness Framework.

International Journal of Older People Nursing, 7(2), 95-104. DOI: https://doi-

org.pc124152.oulu.fi:9443/10.1111/j.1748-3743.2010.00233.x

Mokkink, L.W., Terwee, C.B., Knol, D.L., Stratford, P.W., Alonso, J., Patrick, D.L., Bouter, L.M. \& de Vet, H.C.W. (2010). The COSMIN checklist for evaluating the methodological quality of studies on measurement properties: A clarification of its content. BMC Medical Research Methodology.2010 10:22. DOI: $10.1186 / 1471-2288-10-22$

Munro, B.H. (2005). Statistical methods for health care research (4th ed.). Philadelphia, PA: Lippincott, Williams \& Wilkins.

NMC (2010). Standards for competence for registered nurses. Retrieved from: https://www.nmc.org.uk/globalassets/sitedocuments/standards/nmc-standards-for-competence-forregistered-nurses.pdf

Nursing and Midwifery Board on Ireland (2019). Considerations in determining scope: Competence. Retrieved from: https://www.nmbi.ie/Standards-Guidance/Scope-of-Practice/Considerations-inDetermining-Scope/Competence

Ministry of Justice (1999). Personal Data Act 523/1999. Retrieved from: http://www.finlex.fi/en/laki/kaannokset/1999/19990523

Pett M.A., Lackey N.R. \& Sullivan J.J. (2003). Making Sense of Factor Analysis. The Use of Factor Analysis for Instrument Development in Health Care Research. Sage Publications, Thousand Oaks, CA.

Polit, D.F., \& Beck, C.T. (2007). Focus on research methods. Is the CVI an acceptable indicator of content validity? Appraisal and recommendations. Research in Nursing \& Health, 30, 459-467.

Polit, D.F., \& Beck, C.T. (2012). Nursing research. Generating and assessing evidence for nursing practice (9th ed.). Philadelphia, PA: Lippincott, Williams \& Wilkins.

Räsänen, P., Kanste, O., Elo, S. \& Kyngäs, H. (2014). Factors associated with the self-care of homedwelling older people. Journal of Nursing Education and Practice, 4(8), 2014.

Salin, S., Hautsalo, K., Vänni, K., Seitsamo, S. \& Yli-Koivisto, L. (2020). Finnish nurse students' attitudes towards older adults and the teaching of gerontological nursing - A survey study. Nursing Education Today, 88. DOI: https://doi.org/10.1016/j.nedt.2020.104379 
Savage, C.L. (2019). Public/Community Health and nursing practice: Caring for populations (2nd ed). Philadelphia, PA: F.A Davis.

Selvi, S.T. (2017). Documentation in nursing practice. International Journal of Nursing Education, 9(4), 121-123. DOI: http://dx.doi.org.pc124152.oulu.fi:8080/10.5958/0974-9357.2017.00108.8

Stang, J. (2015). Ethics in action: Conducting ethical research involving human subjects: A primer. Journal of the Academy of Nutrition and Dietetics, 115(12), 2019-2022.

Suhonen, R., Stolt, M., Launis, V. \& Leino-Kilpi, H. (2010). Research on ethics in nursing care for older people: A literature review. Nursing Ethics, 17(3), 337-352.

Szanton, S.L., Roth, J., Nkimbeng, M., Savege, J.\& Klimmek, J. (2014). Improving unsafe environments to support aging independence with limited resources. Nursing Clinics of North America, 49(2), 133-145. DOI: 10.1016/j.cnur.2014.02.002.

Söderhamn, O., Lindencrona, C. \& Gustavsson, S.M. (2001). Attitudes toward older people among nursing students and registered nurses in Sweden. Nursing Education Today, 21(3), 225-229.

Vaportzis, E., Clausen, M.G. \& Gow, A.J. (2017). Older adults perceptions of technology and barriers to integrating with tablet computers: A focus group study. Frontiers in Psychology, 8, 1687. DOI: $10.3389 /$ fpsyg.2017.01687

Wadensen, B., Engholm. R., Fahlström, G. \& Hägglund, D. (2009). Nursing staff's description of a good encounter in nursing homes. International Journal of Older People Nursing, 4(3), 203-10. DOI: 10.1111/j.1748-3743.2009.00170.x. Epub 2009 Jun 23.

Wandke, H., Wandke, H., Sengpiel, M. \& Sönksen, M.

(2012). Myths about older people's use of information and communication technology. Gerontology, 5 8, 564-570. https://doi.org/10.1159/000339104.

WHO (2001). International classification of functioning, disability and health. Geneva, Switzerland: WHO.

WHO (2003). WHO Europe gerontological nursing curriculum. Retrieved

from: http://www.euro.who.int/_data/assets/pdf_file/0018/102267/e81554.pdf.

WHO (2015). World report on ageing and health. Retrieved from: https://apps.who.int/iris/bitstream/handle/10665/186463/9789240694811_eng.pdf;jsessionid=EB76B 27EB6E16BE64E27A07B47046231? sequence=1

WHO (2018). Ageing and health. Retrieved from: https://www.who.int/news-room/factsheets/detail/ageing-and-health

WHO (2020a). Nutrition for older persons. Retrieved from: https://www.who.int/nutrition/topics/ageing/en/index1.html.

WHO (2020b). Process of translation and adaptation of instruments. Retrieved from: https://www.who.int/substance_abuse/research_tools/translation/en/ 
Table 1. Respondents demographics

\begin{tabular}{ll}
\hline Characteristics & Participants $(\mathrm{n}=273)$ \\
\hline Gender, $\mathrm{n}(\%)$ & $234(85.7 \%)$ \\
Female & $39(14.3 \%)$ \\
Male & $0(0 \%)$ \\
Other & \\
& \\
Education, $\mathrm{n}(\%)$ & $88(32.2 \%)$ \\
Vocational qualification & $120(44 \%)$ \\
College degree & $65(23.8 \%)$ \\
Another professional & \\
& \\
School year, n (\%) & $57(20.9 \%)$ \\
$2^{\text {nd }}$ & $98(35.9 \%)$ \\
$3^{\text {rd }}$ & $116(42.5 \%)$ \\
$4^{\text {th }}$ & $2(0.7 \%)$ \\
$5^{\text {th }}$ & \\
& \\
Study type, $\mathrm{n}(\%)$ & $166(60.8 \%)$ \\
Day-studying & $107(39.2 \%)$ \\
Multiform-studying &
\end{tabular}


Figure 1. The three phases of the GeroNursingCom instrument development and testing process

Phase 1. Establishing a theoretical background/ Item generation

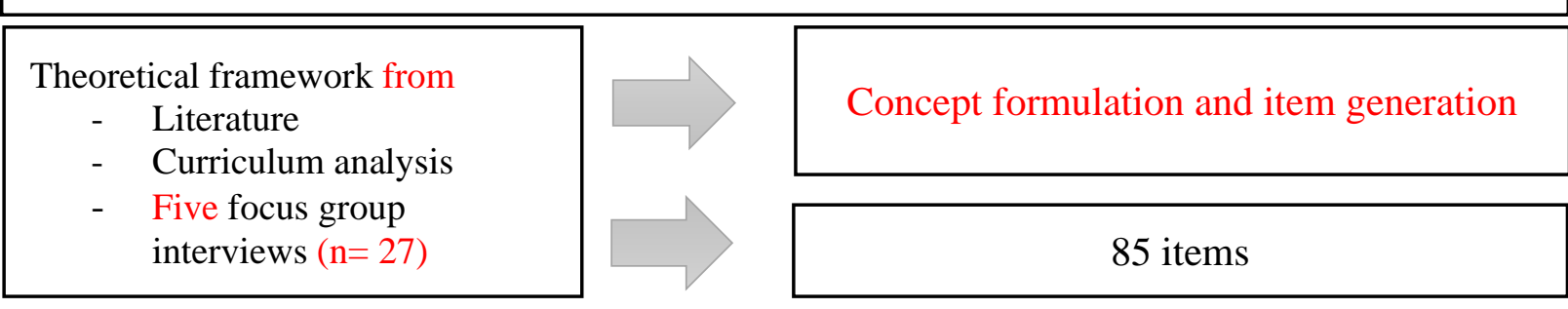

\section{Phase 2. Face and content validity testing}

Two rounds of expert

evaluation $(n=9)$

Pilot study $(\mathrm{n}=36)$
Face and content validity

1) Content Validity Index:

0.86 (relevancy) and 0.90 (clarity)

2) Content Validity Index:

0.99 (relevancy) and 0.98 (clarity)

\section{3 items}

Phase 3. Examining structural validity

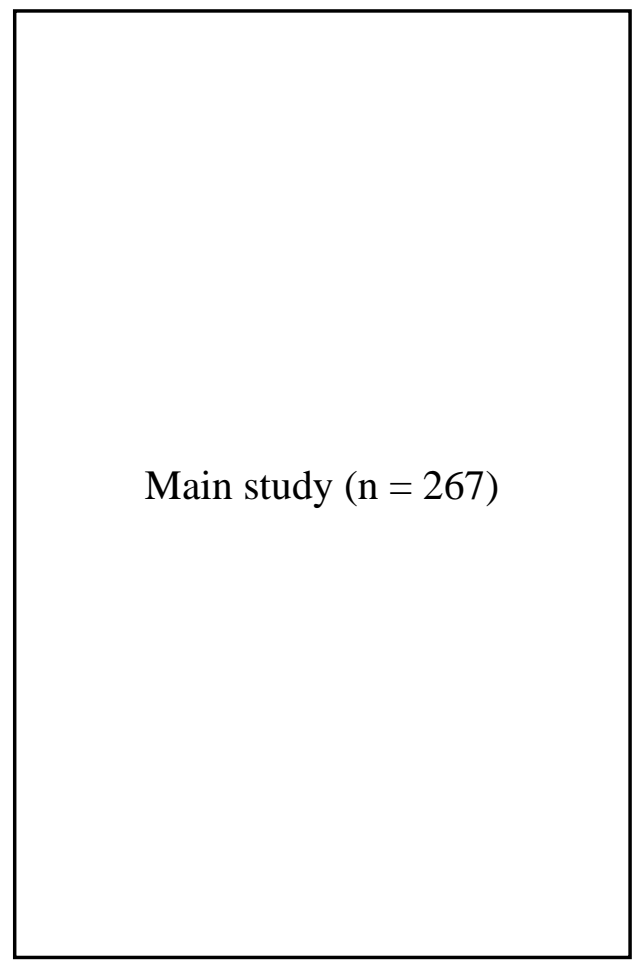

\section{1-factor model}

- Appreciative encounters and interactions with older people ( 7 -items)

- $\quad$ Medication for older people (5 -items)

- Nutrition for older people

(6 -items)

- $\quad$ Safe living environment for older people (5 items)

- Supporting the functioning of older people (9 -items)

End-of-life care (4 -items)

- Developing one's competencies (4 -items)

- Supporting an older person's mental well-being (4 -items)

- $\quad$ Supporting an older person's sexuality (3 -items)

- Guiding self-care among older people (3 -items)

- $\quad$ Responding to challenging situations (3 -items)

Phase 4. Testing internal consistency

Main study $(\mathrm{n}=267)$

Cronbach's alpha 0.75-0.89

53 items 